\title{
PRESENTACIÓN
}

\section{Dos aniversarios, múltiples desafíos. Las relaciones de México con China y Corea del Sur}

DOI: $10.32870 /$ mycp.v1i2.389

\author{
José Jaime López Jiménez ${ }^{1}$ \\ Santiago Acves Villalvazo ${ }^{2}$ \\ Editores \\ José Luis León Manríquez ${ }^{3}$ \\ Opinión invitada
}

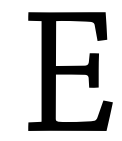

n 2012 se cumplen 40 años de relaciones diplomáticas entre México y la República Popular China (RPC), así como medio siglo de relaciones formales con la República de Corea o Corea del Sur. Estos eventos ofrecen la oportunidad de reflexionar en torno a los logros, límites y posibilidades de ambos vínculos bilaterales. Los aniversarios coinciden con procesos de transición política en los tres países. México estrenó un gobierno priista el $1^{\circ}$ de diciembre, después de doce años de administraciones panistas. China también se encuentra en un proceso de sucesión política, pues en marzo de 2013 el Presidente Hu Jintao y el Premier Wen Jiabao habrán dejado la conducción política a una nueva generación de dirigentes. Corea del Sur no

1. Profesor investigador del Departamento de Estudios del Pacífico, del Centro Universitario de Ciencias Sociales y Humanidades de la Universidad de Guadalajara, y miembro del SNI.

2. Profesor del Instituto Tecnológico de Estudios Superiores de Occidente (ITESO)

3. Profesor investigador de la Universidad Autónoma Metropolitana-Xochimilco, México, y miembro del SNI. 
se queda atrás, ya que el 19 de diciembre celebró su decima octava elección presidencial desde su fundación en 1948. El ganador o ganadora ejercerá el poder durante cinco años hasta el 2018.

Más allá de la diplomacia y las demostraciones de amistad mutua, las relaciones contemporáneas entre México y los países del noreste asiático están altamente influenciadas por el factor económico. Como se muestra en la gráfica 1, China y Corea del Sur constituyen importantes socios comerciales de México. En la década del 2000 la RPC irrumpió de manera acelerada en las relaciones económicas internacionales del país. A mediados de ella, el volumen total del comercio chino-mexicano superó al comercio de México con América Latina, a pesar de la contigüidad geográfica de esa región. En 2011, la RPC se mantenía, con 58,213 millones de dólares en comercio total, como el segundo socio comercial de México, después de Estados Unidos. En lo que respecta a Corea del Sur, la gráfica muestra un aumento sostenido de las transacciones bilaterales, que pasaron de 36 millones de dólares en 1990, a 15,185 millones de dólares en 2011; con ello, ese país se afirma como el sexto socio comercial de México. Un signo adicional de la relación de México con China y Corea son los recurrentes números rojos, situación que contrasta con América latina y que se expresa en la gráfica 2.

\section{Gráfica 1}

Comercio total de México con la RPC y Corea en comparación con América Latina, 1990-2011 (en miles de dólares EUA)

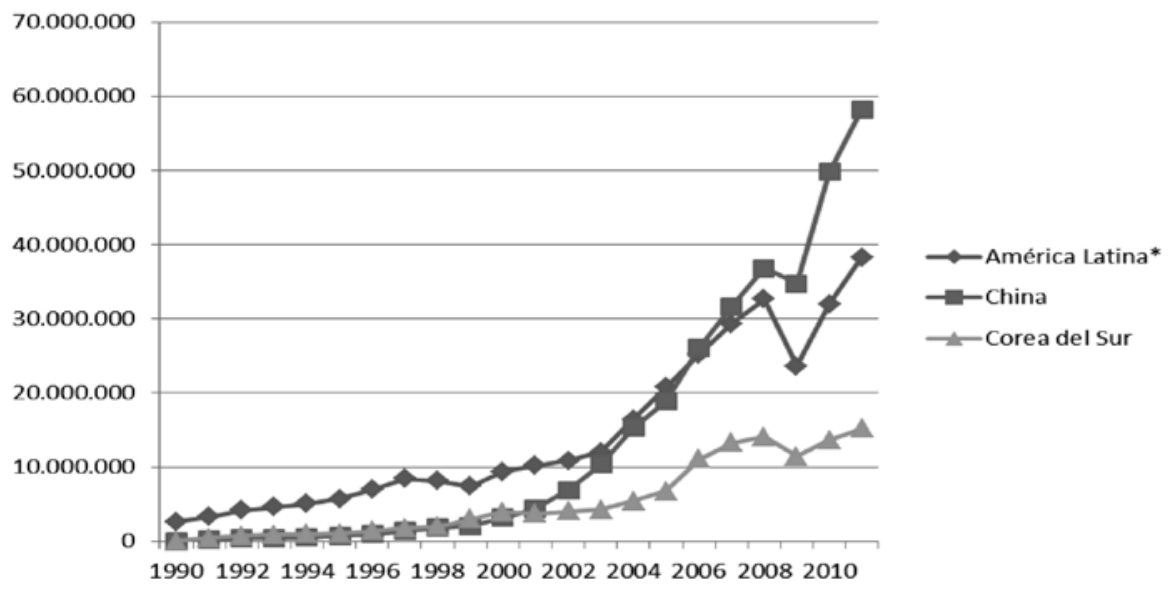

Fuente: Secretaría de Economía, con base en datos de Banxico. 


\section{Gráfica 2}

Balanza comercial de México con la RPC y Corea del Sur en comparación con América Latina, 1990-2011 (en miles de dólares EUA)

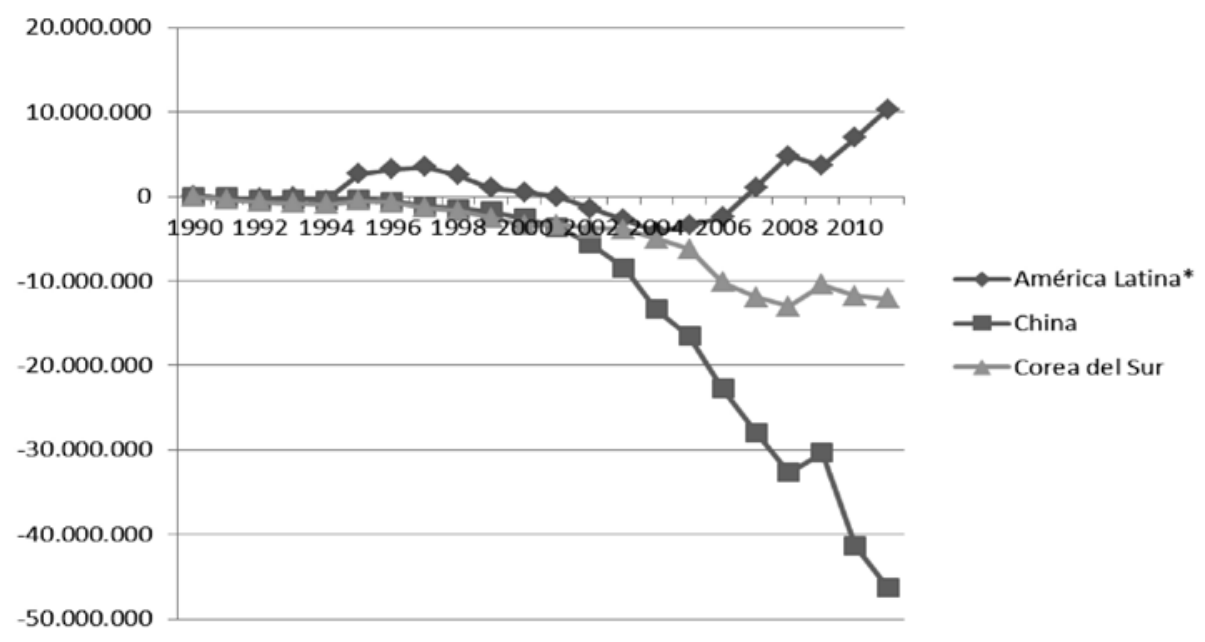

Fuente: Secretaría de Economía, con base en datos de Banxico.

Si bien los vínculos contemporáneos de México con ambos países asiáticos aparecen modelados por la economía, la historia también ocupa un lugar importante. Si se toma como punto de partida la época colonial, la entidad Nueva España-México ha sostenido relaciones con China por más tiempo que con la mayoría de los países del mundo, a excepción de los europeos. La intermitencia ha sido, empero, un elemento recurrente de esta historia. Desde 1543, cuando las naves españolas encontraron una ruta a lo que hoy se conoce como Filipinas, se inició un comercio eminentemente triangular con la China de las dinastías Ming (1368-1644) y Qing (1644-1912). Los intercambios de plata novohispana por muebles, telas, seda y especias se sucederían de manera regular durante más de dos siglos.

La inestabilidad provocada por la Guerra de Independencia en México derivó en la suspensión de la ruta transpacífica a Manila en 1815. Hacia finales del siglo XIX y principios del XX, actores públicos y privados buscaron, sin éxito, reabrir los caminos del Galeón de Manila. Pese a ello, las relaciones con China y el mundo asiático fluían, si bien en un plano social. Desde mediados de siglo XIX, en efecto, iniciaron varias oleadas de migraciones chinas hacia México y otros países latinoamericanos, en su mayoría trianguladas desde 
Estados Unidos. Por entonces, el milenario Imperio Celeste comenzaba a vivir una crisis terminal y sus súbditos buscaban nuevos horizontes en otras partes del mundo.

En 1899 se firmó el Tratado de Amistad, Comercio y Navegación entre un México porfiriano en auge y una China Qing en declive. Amén del reconocimiento mutuo, el Tratado buscaba manejar con más fluidez el fenómeno migratorio. La continuidad de éste generó en México un fuerte racismo antichino, que se expresó en masacres durante la etapa armada de la Revolución Mexicana (1910-1920) y en un reiterado asedio a las comunidades chinas asentadas en los estados de Baja California, Sinaloa y Sonora a lo largo de los años veinte. Estos hechos enrarecieron la relación bilateral por un largo tiempo. De hecho, en 1921 México buscó denunciar, sin éxito, el Tratado de Amistad de 1899.

Tras la caída de la dinastía Qing y el consecuente establecimiento de la República en 1912, China vivió un siglo xx convulso, dividida entre nacionalistas y comunistas. Ambas fuerzas pusieron sus diferencias entre paréntesis para hacer frente a la invasión japonesa (1937-1945). Después de la Segunda Guerra Mundial, la división política ingresó en una nueva fase, que se resolvería con la toma del poder por los comunistas y la huida de los nacionalistas a Taiwán en 1950. A causa de la dinámica global de la Guerra Fría, América Latina -Cuba castrista excluida, México incluido- optó por reconocer al gobierno de Taiwán como representante de China. Tal situación se mantendría hasta principios de los setenta cuando, secundando la actitud de las grandes potencias occidentales, los países latinoamericanos establecieron relaciones con la RPC. Así, México inició relaciones con la RPC en 1972, durante la visita del entonces presidente Luis Echeverría a Beijing.

Las relaciones diplomáticas y culturales se caracterizaron, en las primeras décadas, por la cordialidad. Ambos países compartían visiones comunes sobre algunos temas en la agenda multilateral, amén de intercambiar importantes contingentes de estudiantes y académicos en instituciones como El Colegio de México. El comercio era más bien escaso y el exiguo intercambio comercial favorecía a México. Esto habría de cambiar en los noventa, con la veloz reaparición de China en las grandes ligas de la economía internacional.

Como ya hemos mostrado en las gráficas 1 y 2, el comercio y el déficit con China crecieron vertiginosamente desde mediados de los noventa. Las exorbitantes importaciones de manufacturas chinas, en particular bienes de consumo de bajo costo, han inundado los mercados populares y de clase 
media. Estos productos compiten con las mercancías mexicanas. El problema se agrava por el ritmo con el que los productos chinos desplazaron a las exportaciones mexicanas en el mercado estadounidense, aunque en los últimos años la situación se ha revertido parcialmente. La competencia comercial chino-mexicana ha provocado una gran cantidad de controversias comerciales, quejas del empresariado mexicano y la percepción generalizada de que China representa una amenaza más que una oportunidad. Sin lugar a dudas, puede decirse que el déficit comercial es el tema central de la agenda bilateral en los últimos tres lustros.

La reacción mexicana es una mezcla de ignorancia, prejuicio e ineptitud que se puede apreciar a distintos niveles: en desafortunadas declaraciones por parte de altos funcionarios mexicanos, empezando por los presidentes Vicente Fox y Felipe Calderón; en notas periodísticas caracterizadas por la desinformación, el prejuicio y el sensacionalismo, o bien en manifestaciones contra la importación de textiles, zapatos y otras manufacturas chinas. La existencia de instituciones académicas mexicanas que realizan investigaciones sobre distintos aspectos de la RPC no logra contrapesar la carga de indiferencia, miedo, prejuicio e inacción que caracterizan a gobierno, medios y no pocos empresarios.

A riesgo de simplificar una realidad compleja, es posible argumentar que la vinculación chino-mexicana se ha mantenido sobre dos ejes eminentemente conflictivos: las migraciones a partir de mediados del siglo XIX y el déficit comercial desde finales del siglo Xx. ¿Cómo se podría construir una relación más positiva para el siglo XXI? ¿Qué debe hacer México para estructurar una relación que trascienda los problemas derivados de un déficit comercial recurrente? ¿Qué potencial de acción conjunta existe en los campos político y cultural?

Una respuesta obvia, pero no necesariamente adecuada, es la que ha propuesto, entre otros, el miembro del Instituto para América Latina de la Academia China de Ciencias Sociales, Xu Shicheng, en el sentido de establecer un tratado de libre comercio (TLC) entre ambos países. Esta idea fue expresada también por Gabriel Quadri, candidato del Partido Nueva Alianza (PANAL) en el segundo debate de la campaña presidencial mexicana que tuvo lugar en junio de 2012. Ninguno de los otros tres participantes en la contienda se pronunció sobre el tema, pero consideramos que, por sí misma, dicha propuesta dista de resolver el núcleo conflictivo de la relación bilateral. Pensar-como se hacía en los años noventa- que los TLC pueden sustituir a una política exterior integral 
resulta una estrategia inapropiada para un país que, como México, podría utilizar muchos elementos para considerarse potencia emergente.

Un TLC con China parece una política más conveniente para países relativamente pequeños, con alta propensión a exportar materias primas y una densidad industrial mediana o escasa, como es el caso de Chile o Perú o Costa Rica. No lo es tanto para México, cuyas exportaciones manufactureras compiten con China, se orientan mayoritariamente al mercado estadounidense y carecen de un horizonte significativo de crecimiento en ese país. Debe recordarse, además, que la mayoría de los TLCs firmados por México no necesariamente han contribuido a diversificar las exportaciones del país. La imposibilidad de cubrir las cuotas en ciertos productos fijadas en el Acuerdo de Asociación Económica México-Japón de 2005 es ilustrativa de este hecho.

La necesaria construcción de nuevos arreglos con China debería responder a la siguiente pregunta: ¿Qué debe buscar México en su relación con la RPC, más allá de reducir un masivo déficit comercial, mitigar la competencia de los productos manufacturados en el mercado norteamericano y aumentar la escasa inversión extranjera directa de China en el país? Tales asuntos son estructurales y difícilmente desaparecerán de la agenda bilateral a partir de la sola voluntad política. Sin embargo, consideramos que existen amplias avenidas para estructurar una vinculación que concilie los intereses nacionales de México con las posibilidades de acción conjunta con la RPC, actor clave en la creación de un orden mundial policéntrico en el siglo Xxi. Párrafos adelante avanzaremos algunas propuestas en este sentido.

Con Corea del Sur se cumplen cinco décadas de relación diplomática. Pese a sus reducidas dimensiones, la República de Corea es uno de los socios económicos más importantes para México en el Este Asiático, solo después de China y Japón, y por encima de India. Los vestigios de las relaciones datan de inicios del siglo Xx, cuando más de un millar de coreanos fueron transportados con engaños a México y sometidos a una virtual esclavitud en las haciendas henequeneras de Yucatán. El gobierno mexicano no respondió de forma convincente a las preocupaciones del Reino de Choson, entonces muy débil y a punto de convertirse en una colonia japonesa.

Al contrario de la situación china, la migración coreana no incidió tanto en el fomento del racismo, ya que después de la Revolución los coreanos se fueron integrando paulatinamente en la sociedad mexicana $y$, en muchos casos, experimentaron un acelerado proceso de mestizaje. De todas maneras, en la Segunda Guerra Mundial los coreanos residentes en México se quejaban 
de que algunos sectores de la población los confundían con japoneses, en un momento en que México estaba en situación de guerra con los países del Eje.

$\mathrm{Al}$ igual que con China, la relación bilateral con Corea del Sur se vería condicionada por la Guerra Fría. Si bien México suscribió la postura de las Naciones Unidas, que reconocía al Sur como representante legítimo de la nación coreana, Tlatelolco mantendría una suerte de "distancia amistosa", reflejada en la lenta respuesta ante el ofrecimiento de relaciones por parte del gobierno surcoreano. Si bien las relaciones diplomáticas iniciaron en 1962, México abrió su embajada en Seúl en 1978 y solo nombró un embajador hasta 1987. México no quería verse envuelto en la división ideológica y geopolítica que se vivía en la península coreana, máxime cuando Asia aparecía en un lejano sitio de sus prioridades de política exterior.

A partir de los años noventa, el carácter superficial y aún simbólico de las relaciones con países que parecían tan alejados de México se fue rompiendo. Ante la firma del Tratado de Libre Comercio de América del Norte (TLCAN), numerosas empresas japonesas y surcoreanas comenzaron a asentarse en el país para buscar un acceso más franco al mercado norteamericano. Estas compañías han practicado un comercio intra-firma, que a su vez ha detonado las importaciones mexicanas desde el noreste asiático y ha propiciado los recurrentes números rojos en la balanza comercial con Corea del Sur que se consignaron en la gráfica 2. Los insumos importados se ensamblan en las maquiladoras mexicanas, se exportan a Estados Unidos y contribuyen al superávit comercial de México con ese país.

Aunque no se limita a los intercambios económicos, el grueso de la relación con la República de Corea se ha concentrado en ellos. En este contexto se inscribe la prolongada pero infructuosa negociación de un TLC entre ambos países. Este comenzó a prepararse en 2004, cuando un grupo de expertos de ambos países inició una serie de reuniones orientadas a proponer estrategias para la consolidación de las relaciones económicas. Por entonces, y a diferencia de su postura internacional en los noventa, Corea del Sur ya había ingresado en una búsqueda de TLCs en la Cuenca del Pacífico. Seúl consideraba que éstos resultaban indispensables para fortalecer su estrategia de promoción de las exportaciones. Así, procedió a firmar su primer TLC con Chile en 2004, seguido de instrumentos similares con Singapur, India y la Asociación de Naciones del Sureste Asiático (ANSEA).

Contra lo que se esperaba inicialmente, la negociación comercial mexicano-surcoreana ha resultado muy azarosa. El acuerdo inicial entre los dos 
países fue avanzar hacia un Acuerdo de Complementación Económica (ACE), cuyas negociaciones iniciaron en febrero de 2006. En ese año se efectuaron dos rondas más, pero el proceso se detuvo a partir de junio. Hubo de transcurrir más de un año para que, en agosto de 2007, se anunciase el lanzamiento de negociaciones para un TLC en toda su forma. Después de dos rondas, celebradas en diciembre de 2007 y junio de 2008, las pláticas se estancaron de nuevo. No pudieron reactivarse pese a la visita del presidente surcoreano Lee Myung-Bak a la Ciudad de México del 20 de junio al 2 de julio de 2010 y al cordial encuentro de ambos mandatarios en la cumbre del Grupo de los 20 (G-20) celebrada dos años más tarde en Los Cabos.

Ante estas dificultades, consideramos que México y la República de Corea no deben supeditar su relación a un TLC cuyo destino es más que incierto a causa de las resistencias y el poder de veto del sector privado mexicano. La no suscripción de ese acuerdo comercial difícilmente afectará los flujos de comercio e inversión que, como el agua tras la lluvia, han encontrado su camino de manera espontánea desde hace varias décadas. Existen, además, otros elementos de identidad común que permitirían cimentar una relación más profunda. Por ejemplo, ambos países son economías orientadas a la exportación manufacturera y su dimensión es similar. A decir del Banco Mundial, en 2011 México fue la economía numero 14 y Corea del Sur la 15. En lo político, los dos países han vivido prolongadas experiencias de vecindad con grandes potencias $\mathrm{y}$, desde finales de los años ochenta, han experimentado transiciones paralelas hacia sistemas pluralistas.

Las relaciones de México con China y Corea del Sur resultan muy relevantes en la construcción de nuevos esquemas de vinculación con Asia- Pacífico, en un momento en el que el centro de gravitación de la economía mundial se desplaza crecientemente hacia dicha región. Por ello, restructurar ambas relaciones bilaterales aparece como un pendiente del nuevo gobierno. A manera de ejemplo, y sin la intención de agotar los puntos de una posible renovación de la agenda, proponemos las siguientes acciones:

- Profundizar las relaciones políticas orientadas a incidir activamente en la conformación de un nuevo sistema internacional. México constituye, en la escala de prioridades de China, un "socio estratégico". Si la economía no ha ofrecido las posibilidades para sustanciar ese estatus, el reino de la política puede hacerlo mejor. No se trata de que México juegue a alinearse con la potencia emergente y desafíe a Estados Unidos, sino de utilizar el 
expediente chino como un medio de balancear las relaciones internacionales del país. En el caso de la República de Corea las posibilidades de acción conjunta resultan igualmente atractivas.

- Promover temas multilaterales de interés común. La Organización de las Naciones Unidas (ONU), el Grupo de los 20 (G-20) y la participación de China y Corea del Sur en algunos organismos del sistema interamericano constituyen excelentes oportunidades para una acción conjunta. La coincidencia histórica de las votaciones de la RPC y México en la Asamblea General de la ONU es un antecedente concreto de las posibilidades bilaterales de acción colectiva.

- Ampliar la cooperación educativa, académica y cultural. Las posibilidades en este rubro son enormes, pero entre otras acciones se debería multiplicar el número de programas de investigación dedicados al Este Asiático, fomentar el establecimiento de iniciativas que vinculen a sociedad, empresas, academia y gobierno de las partes involucradas y promover la incorporación de cursos de licenciatura y posgrado sobre China y Corea del Sur en los currículos de las instituciones de educación superior mexicanas.

- Instrumentar una política industrial y de información sobre oportunidades de exportación a Asia-Pacífico. Esta estrategia tendría dos componentes: por un lado, estaría orientada a incrementar el componente de insumos mexicanos en las cadenas de valor de las maquiladoras surcoreanas y japonesas asentadas en México. Por otro lado, buscaría aumentar la oferta exportable en ciertos nichos de mercado, como los productos de consumo orientados a las clases medias de China y Corea del Sur.

A 50 años de relaciones coreano-mexicanas y a cuatro décadas de haber establecido relaciones con la RPC, el trecho por avanzar en los intercambios con ambos países es enorme. Elevar la importancia de Corea y China en la canasta de exportaciones mexicanas es una tarea necesaria para reducir la dependencia de Estados Unidos, que se manifiesta de manera perniciosa en crisis mundiales como la de 2008-2009. En el área política, China y Corea del Sur podrían convertirse en socios de gran relevancia para la inserción de México en un mundo que cada vez parece dirigirse más hacia un orden multipolar. Aunque resultan perfectamente factibles, las propuestas anteriores requieren de una voluntad, por parte de las élites políticas y económicas mexicanas, de repensar la estrategia de inserción del país en el sistema internacional de la Posguerra Fría. 
México debe elegir, a conciencia, si quiere seguir siendo un aliado de segundo orden de Estados Unidos, o bien si desea reposicionarse en la arena internacional como una potencia emergente con capacidad de interlocución y de alianzas regionales y mundiales. Si se opta por la primera opción, la política de las últimas cuatro administraciones (1988-2012) deberá aplicarse de manera inercial. La segunda alternativa no sólo requeriría de una modificación radical de la estrategia diplomática, sino de una política económica que supere las mediocres tasas de crecimiento económico registradas desde principios de los ochenta. Si es verdad que el siglo Xxi será el Siglo del Pacífico, nuestra política exterior deberá girar su mirada al Este Asiático, sin desconocer, desde luego, la realidad geopolítica de la vecindad con América del Norte.

El presente número de la revista México y la Cuenca del Pacífico (MYCP) incluye cuatro artículos en su sección de "Análisis" y una reseña. Alfredo Romero, desde una perspectiva histórica, reflexiona en torno a la relación entre México y la República de Corea, enfatizando los sucesos que explican el acercamiento gradual -y tardío- entre ambos países y que dan indicios sobre su posible devenir. En un primer momento, el autor identifica los procesos internos y las condiciones externas que obstaculizaron, a pesar de la disposición de los mandatarios coreanos, la formalización del vínculo entre los dos gobiernos hasta mediados del siglo xx. En esa línea, Romero atribuye a la falta de intereses económicos y políticos, además del desconocimiento de aquel país, como las causas del rechazo del gobierno mexicano a los emisarios coreanos en distintos momentos, hasta la década de los sesenta cuando los contextos enfrentados por ambos países favorecieron el establecimiento de relaciones diplomáticas. En ese sentido, el autor explica cómo la adopción de un modelo económico orientado a la exportación y la búsqueda de legitimidad política del gobierno de Park Chung-hee incentivaron el acercamiento del ex reino de Chonson; mientras que en México, la administración de López Mateos buscó estrechar vínculos con los países asiáticos durante la gira de la buena voluntad en 1962 .

En segundo lugar, con respecto al futuro de la relación, el autor argumenta a favor de un incremento sustancial en la cooperación con Corea del Sur que, además de ser un importante actor regional, puede ofrecer diversos beneficios para México, en especial, debido a las lecciones que podríamos aprender de su proceso de desarrollo. Sin embargo, para que ello ocurra, advierte el académico, es necesario estudiar a Corea del Sur desde una perspectiva interdisciplinaria y actual. Aunado a ello, sugiere, se debe dar celeri- 
dad a la propuesta de creación de un Acuerdo de Asociación Estratégica que permita establecer políticas claras de cooperación, a la creación de un Consejo de Negocios que coordine actividades para la difusión de información y a la promoción de programas de estudio en ambos países.

Jorge Luis Hidalgo por su parte, en su trabajo sobre las relaciones de México con Tailandia, expone que aún cuando el Océano Pacífico es un espacio que a lo largo del tiempo ha servido para comunicar a América con Asia, como hizo la Nao de China para comerciar y vincular a las colonias españolas, los países de uno y otro lado del mismo todavía se conocen poco. De acuerdo con el autor, en el ámbito latinoamericano el desconocimiento es mayor y el sureste asiático se percibe como algo lejano, no sólo geográficamente, sino también en otros campos como el cultural, el social y el comercial. Su trabajo parte de una revisión breve de algunos aspectos de las dos regiones, resaltando los vínculos entre México y Tailandia a lo largo de una relación de casi cuarenta años, con la finalidad de exponer el potencial existente entre ambas regiones y países, y la rica veta a explotar sobre todo por parte del empresariado mexicano. Por otra parte, el autor destaca la limitada atención que se ha puesto, tanto en México como en Tailandia, a la relación bilateral, pese a lo cual la cooperación y el comercio entre ambas naciones han aumentado de manera constante desde 1990. Hidalgo sostiene que esta situación ofrece enormes posibilidades de aprovechar la Cuenca del Pacífico, pero requiere de un esfuerzo conjunto de los sectores público y privado, con el apoyo de la academia.

Ximena Valentina Echenique analiza las causas del déficit comercial de Estados Unidos, desde una perspectiva macroeconómica y estructural, a partir de la década de los noventa, excluyendo los años de la primera crisis financiera del siglo XxI que, para fortuna de los estadounidenses, ayudó a contener el desequilibrio comercial de su país. El trabajo de Echenique examina la coyuntura que marca el desplazamiento de Japón por parte de China como la relación comercial deficitaria más importante de Estados Unidos, para posteriormente enfocarse en las posibles causas de la creciente participación de la República Popular China en el déficit comercial de los norteamericanos. Al final, la autora presenta una comparación de los índices de ventaja comparativa revelados entre el Este de Asia, China y Estados Unidos, con el propósito de exponer una de las causas estructurales más importantes del creciente desequilibrio comercial de este último.

Finalmente, Daniel A. Revollo y Andrea Sáenz-Arroyo, abordan un tema relevante en el campo de las relaciones internacionales, especialmente a partir 
de la década de los noventa, cuando la solución de problemas ambientales se convirtió en uno de los objetivos de la cooperación internacional. En este contexto, la aportación de los autores se basa en un enfoque interdisciplinario, que conjunta la perspectiva histórica y ambiental, para estudiar el caso del abulón en el Pacífico mexicano, específicamente, en la costa de Baja California. De acuerdo con los autores, la pesca de dichos moluscos ha sido fundamental para el desarrollo de esa área desde tiempos remotos, cuando los aborígenes los consumían como fuente de proteína y utilizaban sus conchas como moneda. A mediados del siglo XIX, la pesca de abulón se convirtió en una actividad lucrativa, aprovechada en primer lugar por inmigrantes chinos y japoneses $y$, posteriormente, por cooperativas mexicanas en los años treinta. Empero, señalan los autores, a partir de la década de los cincuenta la producción ha ido en declive a pesar de los intentos del gobierno mexicano de regular dicha actividad.

Con base en lo anterior, los autores recurren a la creación de una línea base de abundancia mediante entrevistas con tres generaciones distintas de buzos de abulón y la consulta de archivos históricos, con la finalidad de determinar las causas del declive y crear políticas adecuadas para la recuperación del abulón; a partir de la cual, concluyen que una de las principales causas de la disminución ha sido la reducción promedio del tamaño de los moluscos, lo que ha significado una disminución de la capacidad reproductiva de la especie en alrededor del 70\%. En virtud de ello, urgen a la creación de una red de reservas protegidas para mantener y recobrar la población de abulón. Dicho análisis puede ser sumamente útil para buscar soluciones en torno a otros recursos naturales de suma importancia para el país.

Expresamos nuestro sincero agradecimiento a todos nuestros colaboradores por el apoyo brindado a México y la Cuenca del Pacífico, a los miembros tanto del Consejo Editorial como del Comité Editorial por su generosa e invaluable labor para preservar la calidad de la revista y al Centro Universitario de Ciencias Sociales y Humanidades de la Universidad de Guadalajara por el apoyo para la publicación de la misma. 